\title{
Ion Pair-Directed Regiocontrol in Transition-Metal Catalysis: A Meta- Selective C-H Borylation of Aromatic Quaternary Ammonium Salts
}

\author{
Holly J. Davis, Madalina T. Mihai, and Robert J. Phipps* \\ Department of Chemistry, University of Cambridge, Lensfield Road, Cambridge CB2 1EW, United Kingdom \\ Supporting Information
}

\begin{abstract}
The use of noncovalent interactions to direct transition-metal catalysis is a potentially powerful yet relatively underexplored strategy, with most investigations thus far focusing on using hydrogen bonds as the controlling element. We have developed an ion pairdirected approach to controlling regioselectivity in the iridium-catalyzed borylation of two classes of aromatic quaternary ammonium salts, leading to versatile metaborylated products. By examining a range of substituted substrates, this provides complex, functionalized aromatic scaffolds amenable to rapid diversification and more broadly demonstrates the viability of ion-pairing for control of regiochemistry in transition-metal catalysis.
\end{abstract}

$\mathrm{T}$ he use of noncovalent interactions to direct transitionmetal catalysis is a potentially powerful yet relatively underexplored strategy, particularly for addressing issues of regioselectivity in synthetic chemistry. Alongside hydrogen bonds, ion-pairing interactions have emerged as a powerful tool for control of enantioselectivity, ${ }^{1}$ but an equally important aspect in which careful control is required is regioselectivity. Important advances have demonstrated that multiple hydrogen bonds are able to provide precise molecular recognition in particular situations, ${ }^{2}$ delivering regioselectivity in reactions such as site-selective oxygenation of $\mathrm{sp}^{3} \mathrm{C}-\mathrm{H}$ bonds, ${ }^{3}$ regioselective hydroformylation of unsaturated carboxylic acids, ${ }^{4}$ and most recently, regioselective arene borylation, ${ }^{5}$ among others (Chart 1, eq 1). ${ }^{6}$ In contrast to this, ion-pairing interactions have not been explored in the context of addressing regioselectivity challenges. If, however, a single electrostatic interaction could be successfully employed to position a reactive metal center via dynamic ion exchange, this could help to reduce the need for a synthetically elaborate "receptor" portion of the catalyst, potentially increasing both practicality and generality (Chart 1 , eq 2 ). It is possible that the perceived lack of directionality of ion pairs when compared with single and particularly multiple hydrogen bonds has inhibited their investigation thus far. Here, we demonstrate ion-pairing to be a viable approach to address issues of regiocontrol in the iridiumcatalyzed borylation of aromatic $\mathrm{C}-\mathrm{H}$ bonds.

Arguably the most common problem of regioselectivity is encountered in functionalization of arenes, making this an ideal forum to test our ion-pairing approach. Iridium-catalyzed $\mathrm{C}-\mathrm{H}$ borylation stands apart in that regioselectivity is largely controlled by sterics, as opposed to electronics or proximity. Consequently, it is very powerful for functionalization of 1,3-

\section{Chart 1}

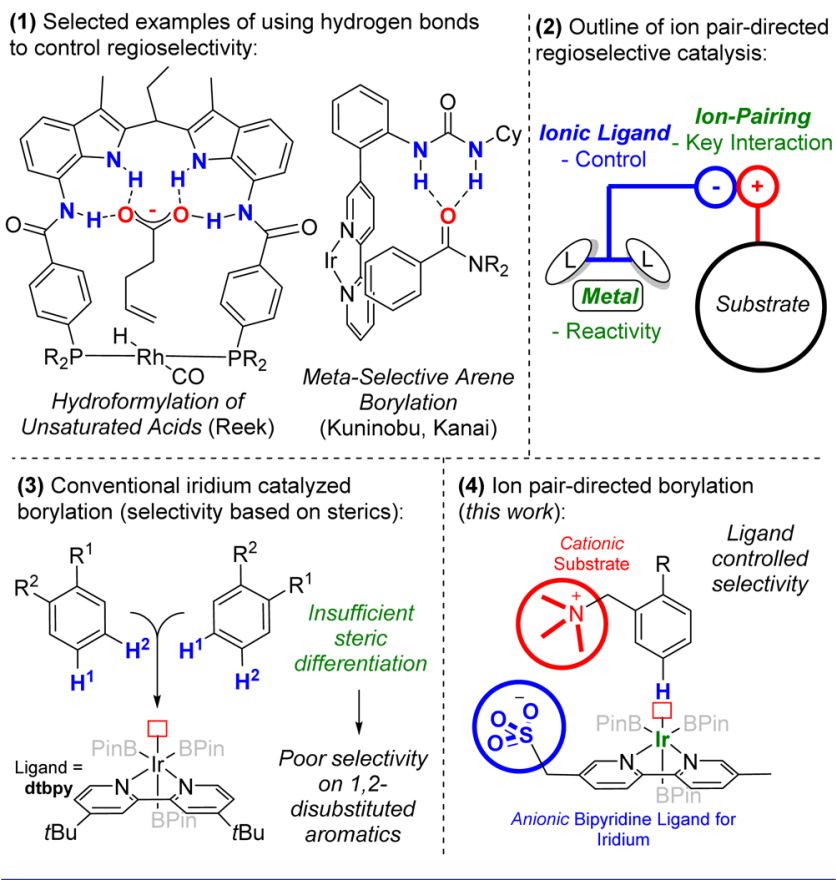

disubstituted arenes. However, monosubstituted or 1,2disubstituted arenes generally give inseparable mixtures of isomers (Chart 1, eq 3), unless a particular substituent can direct either ortho ${ }^{6 c, 8}$ or meta, ${ }^{9}$ or a bulky ligand favor para. ${ }^{10,11}$ In particular, accessing the meta position is desirable due to the relative paucity of methods to access this position, despite recent interest. ${ }^{5,9,12}$ To address this, we sought to investigate cationic arene substrates in iridium-catalyzed borylation, anticipating that the charged center would be able to ion pair with an anionic bifunctional ligand (Chart 1, eq 4). Quaternary ammonium salts are readily accessed, and many methods exist for their elaboration in $\mathrm{sp}^{2}, \mathrm{sp}^{3}$, and heteroatom cross coupling, ${ }^{13}$ reduction, ${ }^{14}$ conversion to boronate esters, ${ }^{13 \mathrm{~d}, 15}$ partners for $\mathrm{C}-\mathrm{H}$ activation, ${ }^{16}$ displacement with ${ }^{18} \mathrm{~F},{ }^{17}$ and $[1,2]$ and $[2,3]$ rearrangement chemistry ${ }^{18}$ among others. In approaching the design of a suitable ion-pairing ligand, we began by elaborating an example of the basic transition state for iridium-catalyzed borylation, as calculated by Singleton, Maleczka, Smith et al. ${ }^{6 c, 19}$ By modifying the structure to append a sulfonate-bearing tether onto the bipyridine back-

Received: August 5, 2016

Published: September 14, 2016 
bone, a productive ion-pairing interaction appears plausible with a quaternized benzylamine substrate undergoing $\mathrm{C}-\mathrm{H}$ oxidative addition at the meta-position. On alkylammonium salts, the positive charge is spread over the methyl/methylene units directly adjacent to the nitrogen, ${ }^{20}$ and thus it is possible that less conventional interactions such as $\mathrm{C}-\mathrm{H}-\mathrm{O}$ hydrogen bonds could provide directionality at close proximity. ${ }^{21} \mathrm{We}$ synthesized anionic bipyridine ligand $\mathbf{L} \mathbf{1}$ in only two steps from inexpensive, commercial material. ${ }^{22}$ Using quaternized 2chlorobenzylamine (1a) as a test substrate, conventional ligand dtbpy gave poor levels of selectivity in both THF and cyclohexane (Table 1, entries 1 and 2), although in THF, a

Table 1. Evaluation of Ligands on Substrate 1a

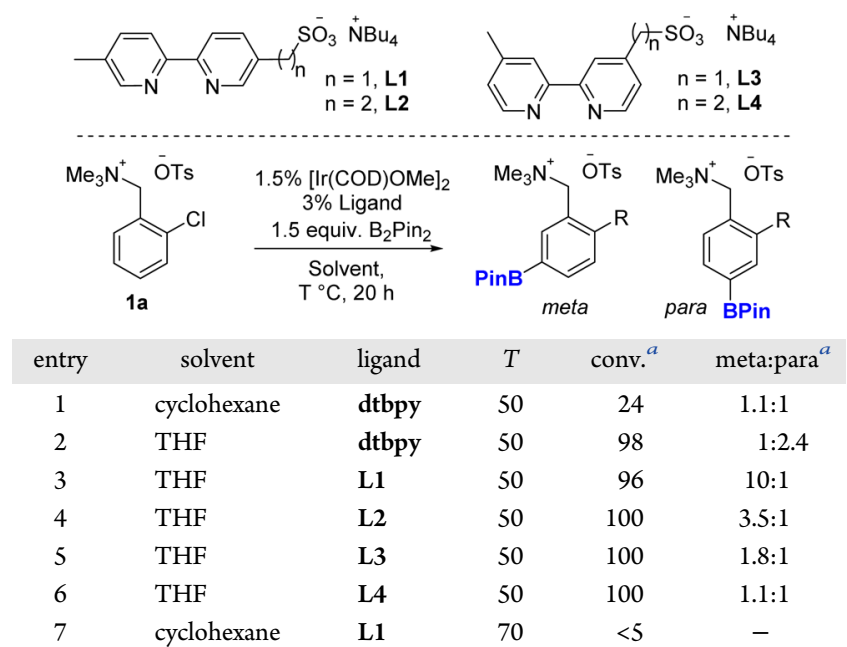

${ }^{a}$ Determined by ${ }^{1} \mathrm{H}$ NMR analysis with reference to an internal standard.

small preference for the para position was observed. Pleasingly, using L1 instead of dtbpy gave 10:1 selectivity for the meta position (entry 3). A ligand with a longer linker (L2) and isomers where the linker extends from the 4-position ( $\mathbf{L} 3$ and L4) all gave poorer selectivity (entries 4 to 6 ), and $L 1$ gave very low conversion in cyclohexane, even at $70{ }^{\circ} \mathrm{C}$ (entry 7).

Control experiments with two neutral surrogates for 1a gave poor selectivity with L1, demonstrating the importance of the positive charge on the substrate and supporting the ion pairing hypothesis (eq 5). ${ }^{22}$ Also, the addition of varying amounts of
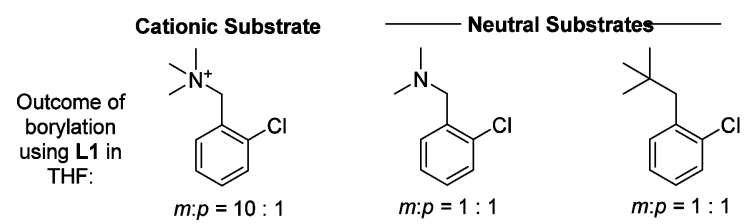

$\mathrm{Bu}_{4} \mathrm{NOTs}$ to the borylation of $\mathbf{1 a}$ using $\mathbf{L} \mathbf{1}$ led to some decrease in the meta-selectivity, potentially due to the excess $\mathrm{Bu}_{4} \mathrm{~N}^{+}$displacing the substrate as ligand counterion and a subsequent increase in nondirected borylation. ${ }^{22}$

With regard to scope of the transformation (Scheme 1), a variety of substituents are tolerated in the ortho position including halogens $(\mathbf{2 a - 2 c})$, electron-withdrawing (2d and $\mathbf{2 e})$ and electron-donating ( $\mathbf{2} \mathbf{f}$ and $\mathbf{2 g}$ ) groups. A Boc-protected amine is also compatible ( $2 \mathbf{h})$. Meta-fluoro substrate $2 \mathbf{i}$ gives high selectivity with $\mathbf{L 1}$, and an ortho-fluoro results in diborylation via initial borylation at the 5-position (2j).
Scheme 1. Substrate Scope for Ion Pair-Directed Borylation of Quaternized Benzylamine Derivatives ${ }^{a}$

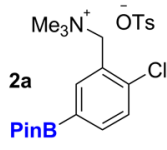

L1, THF: $11: 1,77 \%$ dtbpy, THF: $1: 2,80 \%$

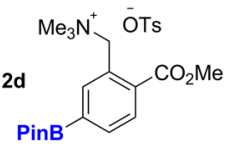

L1, THF: $13: 1(71 \%)$ dtbpy, THF: $1.5: 1(100 \%)$
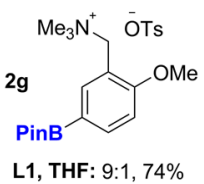
dtbpy, THF: $1: 1.7,80 \%$

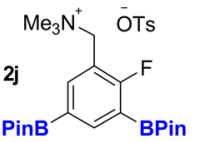

L1, THF: $12 \cdot 1,61 \%$ dtbpy, THF: 2.2:1, $69 \%$

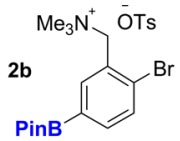

L1, THF: $8: 1,82 \%$ dtbpy, THF: $1: 2.6,51 \%$

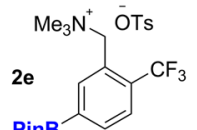

L1, THF: $8: 1,78 \%$ dtbpy, THF: $1: 1.4,63 \%$

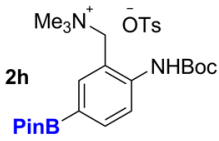

L1, THF: $20: 1,59 \%$ dtbpy, THF: 1.5:1 (52\%)

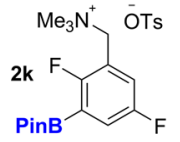

L1, THF: $11: 1,76 \%$

dtbpy, THF: $1.7: 1,70 \%$

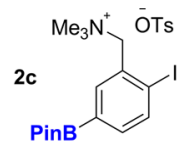

L1, THF: $5.5: 1(82 \%)$ dtbpy, THF: $1: 2.5(73 \%)$

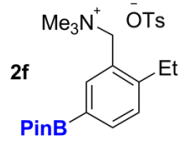

L1, THF: 9:1, 59\% dtbpy, THF: $1: 1.1,53 \%$

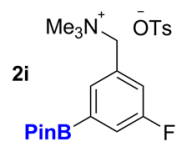

L1, THF: $20: 1,76 \%$ dtbpy, THF: $1.3: 1,52 \%$

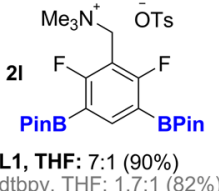

${ }^{a_{T}}$ Typically: Substrate $(0.25 \mathrm{mmol}), \mathrm{B}_{2} \mathrm{Pin}_{2}(0.375 \mathrm{mmol}),[\mathrm{Ir}(\mathrm{COD})$ $\mathrm{OMe}]_{2}(1.5 \mathrm{~mol} \%)$, ligand $(3 \mathrm{~mol} \%)$, solvent $(0.2 \mathrm{M}), 50-70{ }^{\circ} \mathrm{C}$ (see SI for details). Yields shown are isolated except where shown in parentheses (NMR yields with reference to internal standard). Isomeric ratios are meta:para taken from analysis of crude ${ }^{1} \mathrm{H}$ NMR spectra.

Substrates $\mathbf{2 k}$ and $\mathbf{2 l}$ demonstrate that our ion-pairing ligand is able to "reach past" ortho-fluoro substituents in both cases to impart high selectivity in the first borylation. Indeed, in $\mathbf{2 1}$ borylation occurs preferentially adjacent to the fluorine (meta) rather than in the less hindered para-position. In all cases, poor selectivity was observed with standard borylation ligand dtbpy. The products were isolated by precipitation from ether, except in several cases where the products decomposed upon isolation; in these few cases, yields were determined by NMR with reference to an internal standard.

We next investigated whether aniline-derived quaternary ammonium salts may exhibit similar trends (Scheme 2). While we were concerned that moving the arene one carbon closer to the ammonium group could disrupt the selectivity, basic modeling suggested that this substrate class also looked viable according to our hypothesis, since there are a number of different ways in which the cationic substrate and anionic ligand can plausibly associate. In the event, anionic ligand L1 again proved to be a powerful meta-director and provided good to excellent selectivity in most cases, far superior to analogues L2-L4. ${ }^{22}$ As before, the scope was found to be broad with respect to functionality tolerated with electron-withdrawing $(4 a-4 c)$, -donating $(4 d-4 f)$, halogens $(4 a)$, and aromatic groups $(\mathbf{4 g}){ }^{23}$ Heterocyclic substrates (4h and $\left.4 \mathbf{i}\right)$ had a propensity for diborylation due to the reduced steric demand of the aliphatic ring, although $4 \mathrm{~h}$ could be stopped at the mono. Several fluorine-containing substrates underwent selective borylation using $\mathbf{L} \mathbf{1}$ (4j and $\mathbf{4 k}$ ). Furthermore, borylation to give $4 \mathbf{a}$ could be carried out efficiently on gram scale. We also investigated aromatic heterocyclic substrates (Scheme 3). 2- 
Scheme 2. Substrate Scope for Ion Pair-Directed Borylation of Quaternized Aniline Derivatives

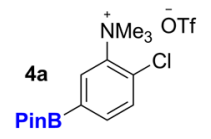

L1, THF: $8: 1,88 \%$

dtbpy, THF: $1: 2,91 \%$

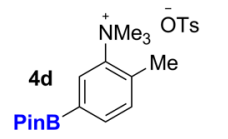

L1, THF: $8: 1,85 \%$ L1, THF: $8: 1,85 \%$
dtbpy, THF: $1.7: 1,(21 \%)$

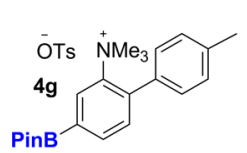

PinB

L1, THF: 9:1, 79\% dtbpy, THF: $1: 1,86 \%$
dit

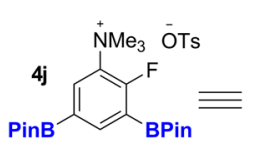

L1, THF: >20:1, 81\% dtbpy, THF: $5: 1,87 \%$

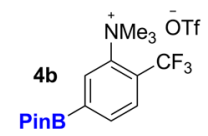

L1, THF: $9: 1,90 \%$ dtbpy, THF: 1:1.2, $88 \%$

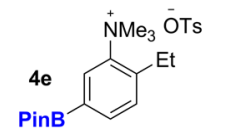

L1, THF: $14: 1,93 \%$ L1, THF: $14: 1,93 \%$
dtbpy, THF: $1.4: 1,87 \%$

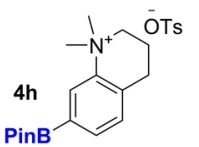

L1, THF: $>20: 1,80 \%$ L1, THF: $>20: 1,80 \%$
dtbpy, THF: $2.1: 1,(67 \%)$

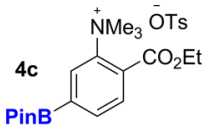

L1, THF: 7:1, (91\%) dtbpy, THF: $1: 1,(98 \%)$

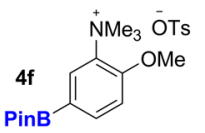

L1, THF: $4: 1,75 \%$ ditbpy, THF: $1: 1.2,95 \%$
dthe

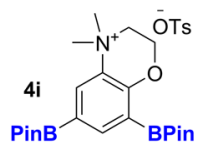

L1, THF: $20: 1,89 \%$ dtbpy, THF: $1.4: 1,73 \%$

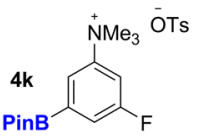

L1, THF: $>20: 1,87 \%$ dtbpy, THF: $2: 1,87 \%$
Scheme 3. Borylation of Aromatic Heterocycles

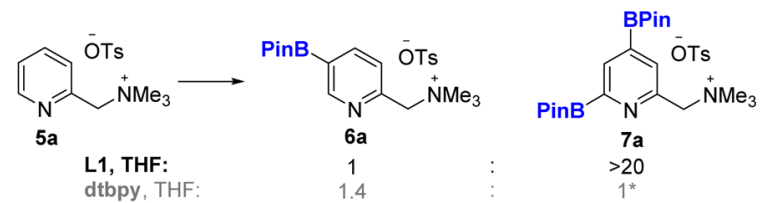

*Mixture of $\mathrm{C} 4$ borylated and C4,6 diborylated

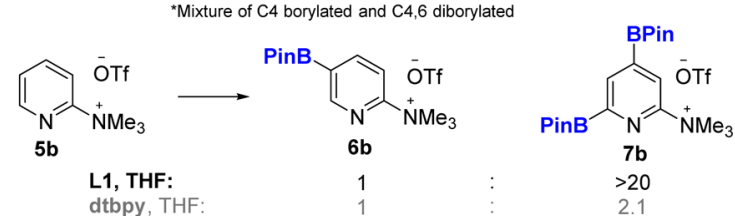

dtbpy, THF
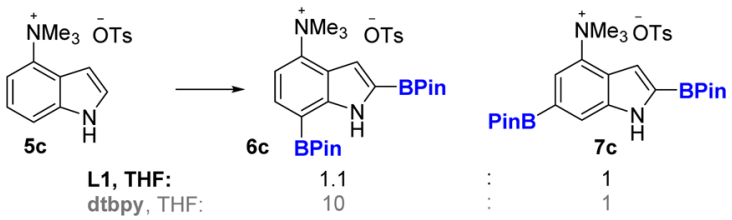

Substituted pyridines generally give mixtures upon borylation and with dtbpy pyridyl ammonium salts $\mathbf{5 a}$ and $\mathbf{5 b}$ gave nonselective 5- and 4,6-diborylation. ${ }^{24}$ In the latter case, borylation at $\mathrm{C} 4$ occurs initially but is followed by a facile second borylation at $\mathrm{C}^{2}{ }^{24 \mathrm{~b}}$ Using $\mathbf{L 1}$ in both cases leads to very high selectivity for the 4,6-diborylated product, indicating high levels of regiocontrol over $\mathrm{C} 4$ vs $\mathrm{C} 5$ borylation. Free $\mathrm{NH}$ indoles are established to undergo initial borylation at the 2position, followed by a second directed borylation at the $\mathrm{C} 7$ position due to a directing effect of the $\mathrm{N}$-heteroatom. ${ }^{24 a, 25} \mathrm{On}$ substrate 5c, the 2,7 diborylated isomer was the predominant product with dtbpy. Despite the innate substrate direction to C7, L1 was able to significantly affect the regiochemical outcome, and roughly equal amounts of $\mathrm{C} 2,6$ and $\mathrm{C} 2,7$ diborylated isomers were obtained.

We examined a selection of derivatives without arene substituents, which resulted in symmetrical diborylation with
$>20: 1$ selectivity in all cases using $\mathbf{L 1}$ (Scheme 4). ${ }^{26}$ As well as unsubstituted versions of earlier substrates $(2 \mathrm{~m}$ and $4 \mathrm{l}$ ), this

\section{Scheme 4. Diborylation of Unsubstituted Arenes}
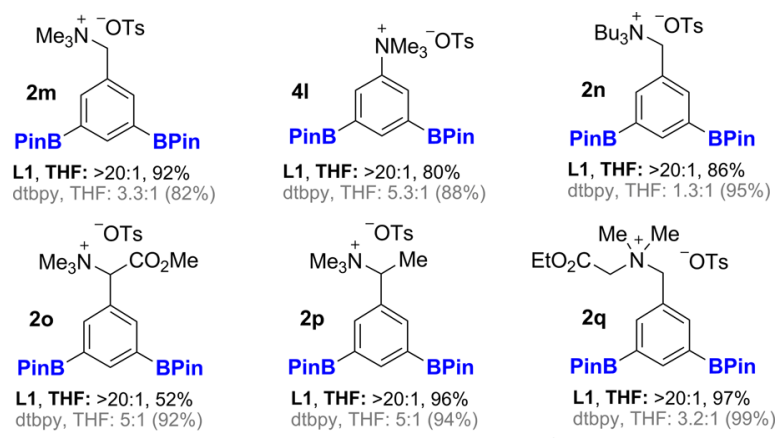

dtbpy, THF: $1.3: 1(95 \%)$
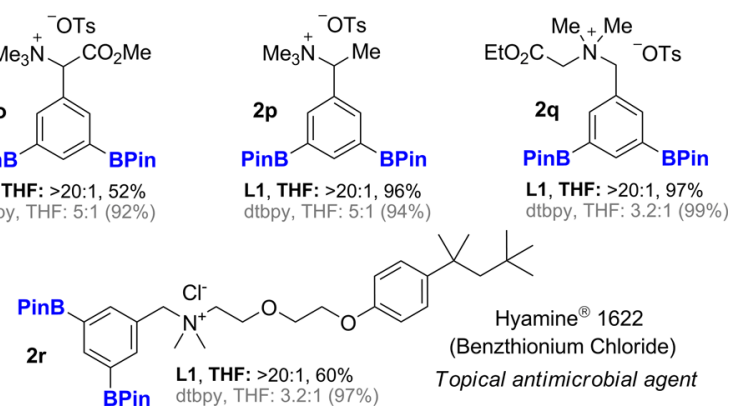

includes a substrate quaternized with butyl groups (2n), benzylammonium salts with $\alpha$-substitution ( 20 and $2 p$ ), and a glycine-derived ammonium salt (2q). We also demonstrate application to the meta-selective diborylation of the antimicrobial surfactant benzthionium chloride $(2 \mathbf{r})$.

To demonstrate the utility of our products, which contain up to three orthogonal handles for cross-coupling, we carried out a borylation/Suzuki coupling of $\mathbf{1 a}$ and used this as the basis for two subsequent palladium-catalyzed cross couplings in an iterative manner (Scheme 5). Notably, we discovered that in

\section{Scheme 5. Application to Iterative Cross-Coupling}

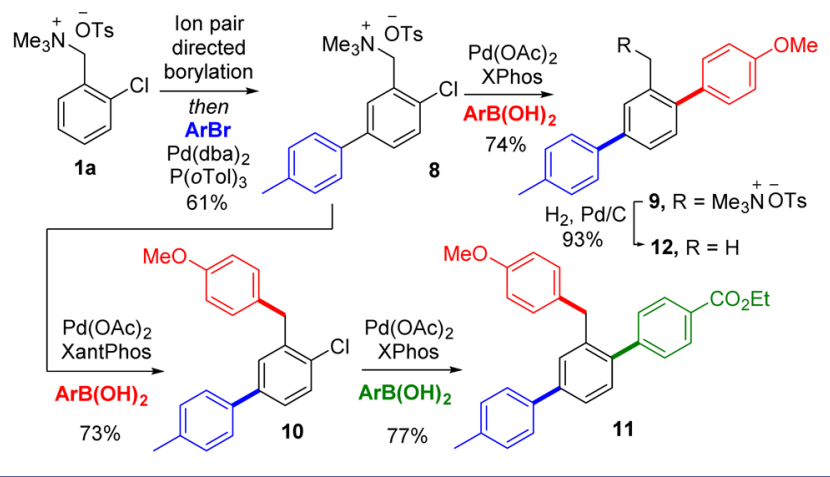

compound $\mathbf{8}$, the ammonium functionality can be selectively coupled with a boronic acid in the presence of the chloride, using $\mathrm{Pd}(\mathrm{OAc})_{2} /$ Xantphos (8 to 10). Conversely, using XPhos selectively couples the chloride and leaves the ammonium untouched ( 8 to 9 ). This ligand-controlled chemoselectivity using palladium catalysis is significant, as previously only nickel catalysis has been used in coupling of benzyl ammonium salts with boronic acids, a protocol not tolerant of halide functionality, limiting application to sequential couplings. ${ }^{13 \mathrm{f}}$ This discovery, together with the extensive cross-coupling literature, ${ }^{13}$ provides ample opportunity for rapid diversification of the versatile aromatic structures accessible using this liganddirected approach to borylation. Furthermore, the ammonium handle can be readily cleaved by hydrogenation, if desired ( 9 to 12). 
We have developed a readily accessed, anionic ligand that engages in a substrate-catalyst ion-pairing interaction to enable meta-selective borylation of two distinct classes of aromatic quaternary ammonium salts. The use of noncovalent interactions to control regioselectivity in transition-metal catalysis is an area of great potential. This study demonstrates the viability of ion-pairing as a powerful tool for the development of new regioselective transformations.

\section{ASSOCIATED CONTENT}

\section{S Supporting Information}

The Supporting Information is available free of charge on the ACS Publications website at DOI: 10.1021/jacs.6b08164.

Crystallographic data (CIF)

Experimental procedures and spectral data (PDF)

\section{AUTHOR INFORMATION}

\section{Corresponding Author}

*rjp71@cam.ac.uk

\section{Notes}

The authors declare no competing financial interest.

\section{ACKNOWLEDGMENTS}

We are grateful to the EPSRC and Pfizer for a CASE studentship (H.J.D.), AstraZeneca for a studentship (M.T.M.) through the AZ-Cambridge Ph.D. Program, the Royal Society for a University Research Fellowship (R.J.P.), the EPSRC and EPSRC U.K. National Mass Spectrometry Facility at Swansea University, and Dr Andrew Bond for X-ray crystallography. We thank Professors Steven V. Ley and Matthew J. Gaunt for support and useful discussions and Dr David Blakemore (Pfizer) and Dr Alan D. Brown for useful discussion.

\section{REFERENCES}

(1) (a) Brak, K.; Jacobsen, E. N. Angew. Chem., Int. Ed. 2013, 52, 534. (b) Mahlau, M.; List, B. Angew. Chem., Int. Ed. 2013, 52, 518. (c) Phipps, R. J.; Hamilton, G. L.; Toste, F. D. Nat. Chem. 2012, 4, 603. (d) Shirakawa, S.; Maruoka, K. Angew. Chem., Int. Ed. 2013, 52, 4312. (e) Hamilton, G. L.; Kang, E. J.; Mba, M.; Toste, F. D. Science 2007, 317, 496. (f) Mukherjee, S.; List, B. J. Am. Chem. Soc. 2007, 129, 11336. (g) Ohmatsu, K.; Ito, M.; Kunieda, T.; Ooi, T. Nat. Chem. 2012, 4, 473. (h) Ohmatsu, K.; Imagawa, N.; Ooi, T. Nat. Chem. 2014, $6,47$.

(2) Dydio, P.; Reek, J. N. H. Chem. Sci. 2014, 5, 2135.

(3) Das, S.; Incarvito, C. D.; Crabtree, R. H.; Brudvig, G. W. Science 2006, 312, 1941.

(4) (a) Dydio, P.; Detz, R. J.; Reek, J. N. H. J. Am. Chem. Soc. 2013, 135, 10817. (b) Šmejkal, T.; Breit, B. Angew. Chem., Int. Ed. 2008, 47, 311.

(5) Kuninobu, Y.; Ida, H.; Nishi, M.; Kanai, M. Nat. Chem. 2015, 7, 712.

(6) For leading examples, see: (a) Grotjahn, D. B.; Miranda-Soto, V.; Kragulj, E. J.; Lev, D. A.; Erdogan, G.; Zeng, X.; Cooksy, A. L. J. Am. Chem. Soc. 2008, 130, 20. (b) Fackler, P.; Berthold, C.; Voss, F.; Bach, T. J. Am. Chem. Soc. 2010, 132, 15911. (c) Roosen, P. C.; Kallepalli, V. A.; Chattopadhyay, B.; Singleton, D. A.; Maleczka, R. E.; Smith, M. R. J. Am. Chem. Soc. 2012, 134, 11350. (d) Rummelt, S. M.; Radkowski, K.; Roşca, D.-A.; Fürstner, A. J. Am. Chem. Soc. 2015, 137, 5506.

(7) (a) Hartwig, J. F. Chem. Soc. Rev. 2011, 40, 1992. (b) Mkhalid, I. A. I.; Barnard, J. H.; Marder, T. B.; Murphy, J. M.; Hartwig, J. F. Chem. Rev. 2010, 110, 890.

(8) (a) Boebel, T. A.; Hartwig, J. F. J. Am. Chem. Soc. 2008, 130, 7534. (b) Crawford, K. M.; Ramseyer, T. R.; Daley, C. J. A.; Clark, T. B. Angew. Chem., Int. Ed. 2014, 53, 7589. (c) Ghaffari, B.; Preshlock, S.
M.; Plattner, D. L.; Staples, R. J.; Maligres, P. E.; Krska, S. W.; Maleczka, R. E.; Smith, M. R. J. Am. Chem. Soc. 2014, 136, 14345. (d) Ishiyama, T.; Isou, H.; Kikuchi, T.; Miyaura, N. Chem. Commun. 2010, 46, 159. (e) Kawamorita, S.; Ohmiya, H.; Hara, K.; Fukuoka, A.; Sawamura, M. J. Am. Chem. Soc. 2009, 131, 5058. (f) Preshlock, S. M.; Plattner, D. L.; Maligres, P. E.; Krska, S. W.; Maleczka, R. E.; Smith, M. R. Angew. Chem., Int. Ed. 2013, 52, 12915. (g) Ros, A.; LópezRodríguez, R; Estepa, B.; Álvarez, E.; Fernández, R; Lassaletta, J. M. J. Am. Chem. Soc. 2012, 134, 4573.

(9) Bisht, R.; Chattopadhyay, B. J. Am. Chem. Soc. 2016, 138, 84.

(10) Saito, Y.; Segawa, Y.; Itami, K. J. Am. Chem. Soc. 2015, 137, 5193.

(11) For rhodium-catalyzed silylation of less sterically defined arenes, see: Cheng, C.; Hartwig, J. F. Science 2014, 343, 853.

(12) For leading examples, see: (a) Zhang, Y.-H.; Shi, B.-F.; Yu, J.-Q. J. Am. Chem. Soc. 2009, 131, 5072. (b) Phipps, R. J.; Gaunt, M. J. Science 2009, 323, 1593. (c) Duong, H. A.; Gilligan, R. E.; Cooke, M. L.; Phipps, R. J.; Gaunt, M. J. Angew. Chem., Int. Ed. 2011, 50, 463. (d) Saidi, O.; Marafie, J.; Ledger, A. E. W.; Liu, P. M.; Mahon, M. F.; Kociok-Köhn, G.; Whittlesey, M. K.; Frost, C. G. J. Am. Chem. Soc. 2011, 133, 19298. (e) Leow, D.; Li, G.; Mei, T.-S.; Yu, J.-Q. Nature 2012, 486, 518. (f) Hofmann, N.; Ackermann, L. J. Am. Chem. Soc. 2013, 135, 5877. (g) Luo, J.; Preciado, S.; Larrosa, I. J. Am. Chem. Soc. 2014, 136, 4109. (h) Tang, R.-Y.; Li, G.; Yu, J.-Q. Nature 2014, 507, 215. (i) Dong, Z.; Wang, J.; Dong, G. J. Am. Chem. Soc. 2015, 137, 5887.

(13) (a) Blakey, S. B.; MacMillan, D. W. C. J. Am. Chem. Soc. 2003, 125, 6046. (b) Reeves, J. T.; Fandrick, D. R.; Tan, Z.; Song, J. J.; Lee, H.; Yee, N. K.; Senanayake, C. H. Org. Lett. 2010, 12, 4388. (c) Xie, L.G.; Wang, Z.-X. Angew. Chem., Int. Ed. 2011, 50, 4901. (d) Zhang, H.; Hagihara, S.; Itami, K. Chem. - Eur. J. 2015, 21, 16796. (e) Basch, C. H.; Cobb, K. M.; Watson, M. P. Org. Lett. 2016, 18, 136. (f) Maity, P.; Shacklady-McAtee, D. M.; Yap, G. P. A.; Sirianni, E. R.; Watson, M. P. J. Am. Chem. Soc. 2013, 135, 280.

(14) Paras, N. A.; Simmons, B.; MacMillan, D. W. C. Tetrahedron 2009, 65, 3232.

(15) (a) Hu, J.; Sun, H.; Cai, W.; Pu, X.; Zhang, Y.; Shi, Z. J. Org. Chem. 2016, 81, 14. (b) Mfuh, A. M.; Doyle, J. D.; Chhetri, B.; Arman, H. D.; Larionov, O. V. J. Am. Chem. Soc. 2016, 138, 2985.

(16) Zhu, F.; Tao, J.-L.; Wang, Z.-X. Org. Lett. 2015, 17, 4926.

(17) Furuya, T.; Klein, J. E. M. N.; Ritter, T. Synthesis 2010, 2010, 1804.

(18) Biswas, B.; Singleton, D. A. J. Am. Chem. Soc. 2015, 137, 14244. (19) Green, A. G.; Liu, P.; Merlic, C. A.; Houk, K. N. J. Am. Chem. Soc. 2014, 136, 4575 .

(20) Dougherty, D. A. Acc. Chem. Res. 2013, 46, 885.

(21) Steiner, T. Chem. Commun. 1997, 727.

(22) See SI for full details.

(23) Due to requirements of synthetic accessibility, some substrates were used as their triflate salts.

(24) (a) Takagi, J.; Sato, K.; Hartwig, J. F.; Ishiyama, T.; Miyaura, N. Tetrahedron Lett. 2002, 43, 5649. (b) Sadler, S. A.; Tajuddin, H.; Mkhalid, I. A. I.; Batsanov, A. S.; Albesa-Jove, D.; Cheung, M. S.; Maxwell, A. C.; Shukla, L.; Roberts, B.; Blakemore, D. C.; Lin, Z.; Marder, T. B.; Steel, P. G. Org. Biomol. Chem. 2014, 12, 7318.

(25) (a) Ishiyama, T.; Takagi, J.; Yonekawa, Y.; Hartwig, J. F.; Miyaura, N. Adv. Synth. Catal. 2003, 345, 1103. (b) Paul, S.; Chotana, G. A.; Holmes, D.; Reichle, R. C.; Maleczka, R. E.; Smith, M. R. J. Am. Chem. Soc. 2006, 128, 15552.

(26) Interestingly, several of these substrates gave higher than expected meta selectivity with dtbpy in THF (2o, 2p, and $4 \mathbf{1})$. Switching to cyclohexane with dtbpy as ligand gave unexpectedly high meta selectivity for these compounds, albeit in generally low conversion to mixtures of mono and diborylated compounds. The substrates in Schemes 1-3 were found to give poor selectivity using dtbpy/cyclohexane, demonstrating that this unusual effect was not general and restricted to substrates with no arene substituents. For further details and screening of $1 \mathrm{a}$ and $1 \mathrm{~m}$ against a range of bipyridine ligands in cyclohexane to probe this, see SI. 